\title{
EVALUATION OF PATIENT'S QUALITY LIFE WITH JOINT AND MUSCLE DYSFUNCTION
}

D0I: $10.36740 /$ WLek202007108

\author{
Igor V. Yaishen, Karina Y. Andrienko, Irina 0. Pereshivaylova, Leah G. Salia, Elena 0. Berezhna \\ KHARKIV NATIONAL MEDICAL UNIVERSITY, KHARKIV, UKRAINE
}

\begin{abstract}
The aim: was the evaluation the patient's quality of life with muscular and joint dysfunction of TMJ with using a modified profile questionnaire at various stages of orthopedic treatment. The study was conducted at the Department of Orthopedic Dentistry on the base of University Dental Center in Kharkiv National Medical University.

Materials and methods: We conducted a clinical examination and subjective analysis of 125 patients aged 20 to 60 years (mean age $38.5 \pm 3$ ), and 80 of them with a reliable diagnosis of dysfunction of TMJ and a control group of 45 patients of the same age without pathology of TMJ.

Our profile questionnaire is intended for filling by the respondent (patient) at the three control stages of orthopedic treatment under the supervision of an orthopedic dentist (before the start of treatment, 1.5 months after the beginning of treatment and 3 months). The data obtained were subjected to a scaling process, converted into percentages to facilitate statistical analysis.

Results: The worst values before and after treatment were found in the $3 \mathrm{rd}$ and 4th age subgroups ( $30.5 \pm 0.60$ and $42.0 \pm 0.7$ points, respectively), with a mean of 10 and $13 \%$, respectively, according to the proposed rating scale. In this case, the indicators have changed 1.3 times in the direction of increase. The highest level of QL was observed in patients of the 2 nd ( $98.7 \pm 0.8$ points) and the 1st subgroups ( $102.3 \pm 0.4$ points), the average value for the three stages of treatment was $78 \%$ and $92 \%$ rating scales. Before of orthopedic treatment, the values were approximately the same.

Conclusions: The using of profile questionnaire of quality of life in patients with muscular and joint dysfunction of the TMJ is appropriate. The questionnaire can be used to evaluate the dynamics of orthopedic treatment of this complex pathology, and it can also be used as a prognostic criterion for the end of the disease.
\end{abstract}

KEY WORDS: temporomandibular joint, muscular and joint dysfunction, analysis, quality of life, orthopedic treatment, modified profile questionnaire

Wiad Lek. 2020;73(7):1350-1354

\section{INTRODUCTION}

The temporomandibular joint (TMJ) is one of the most actively working joints in human body. The complexity of the anatomical structure and biomechanics causes a high frequency of its dysfunction [1].

Dysfunction of the temporomandibular joint holds a special place among dental diseases due to the high prevalence, difficulties in diagnosis and treatment, a difficult and unusual clinical picture, which requires a differentiated approach of doctors of different profiles [2, 3]. As Sellmann H. (2003) noted, in the USA, the cost of treating temporomandibular joint dysfunction is after the treating of malignant tumors and has the second place be the prices of complex treatment.

In the scientific medical literature of recent years, there are articles about the need to change the established views on the diagnosis and treatment of TMG disorders because the emergence and development of this pathology is influenced by a variety of factors $[1,4,5]$. It could be the psycho-emotional felling of patients, traumas of the maxillofacial area, defects of the dental rows, which cause the dysfunction of chewing, the presence of fillings and dentures in the oral cavity, pathological abrasion of hard tissues of teeth, bad habits. Pain is one of the symptoms of the disease, and it can be so significant that patients have impaired function of chewing, swallowing and speech $[6,7]$.
The high attention is being to the need to expand cooperation not only between dentists of different specialties, but also with the cooperation of specialists in different fields of medicine with the obligatory assessment of psychosocial factors.

Many autors (Furberg C.D., Wiklund J., Herlitz J.) note, that it is now advisable to evaluate the effectiveness and cost-effectiveness of different therapies not only on the criteria that are widely used, butalso on specific indicators of quality of life $[8,9]$.

Quality of life in medicine concerns, first and foremost, the state of health, although it is based on subjective perception and is a characteristic of respondents' in physical, psychological, emotional and social states. In most cases, modern medical research uses different methods of determining quality of life.

In nowadays in the world there are developed near 400 quality of life questionnaires. They are widely used in medicine, especially in those areas where the quality of life is most affected by disease $[3,10]$. The analysis of the results makes it possible to characterize the condition of patients with different forms of pathologies. The most common include: EuroQOL (EQ - 5D) developed by European researchers, as well as American questionnaire SF 36 and its modifications (SF-22, SF-20, SF-12).

We can say that the assessment of the quality of life of patients is necessary not only to achieve the planned result 
Table 1. Quantitative indicator of patients with muscular and joint dysfunction of TMJ by gender and age

\begin{tabular}{|c|c|c|c|c|c|c|c|}
\hline \multirow[b]{3}{*}{$\begin{array}{c}\text { № } \\
\text { subgr }\end{array}$} & \multirow[b]{3}{*}{ Age } & \multicolumn{6}{|c|}{ Quantitative indicator } \\
\hline & & \multicolumn{2}{|c|}{ Men } & \multicolumn{2}{|c|}{ Women } & \multicolumn{2}{|c|}{ Total } \\
\hline & & $\begin{array}{l}\text { dysfunction } \\
\text { of TMJ }\end{array}$ & $\begin{array}{c}\text { Without } \\
\text { dysfunction } \\
\text { of TMJ }\end{array}$ & $\begin{array}{c}\text { dysfunction } \\
\text { of TMJ }\end{array}$ & $\begin{array}{c}\text { Without } \\
\text { dysfunction } \\
\text { of TMJ }\end{array}$ & $\begin{array}{l}\text { dysfunction } \\
\text { of TMJ }\end{array}$ & $\begin{array}{l}\text { Without } \\
\text { dysfunction } \\
\text { of TMJ }\end{array}$ \\
\hline 1. & 20-30 years & 6 & 5 & 11 & 5 & 17 & 10 \\
\hline 2. & 30-40 years & 7 & 5 & 12 & 4 & 19 & 9 \\
\hline 3. & 40-50 years & 12 & 5 & 10 & 7 & 22 & 12 \\
\hline \multirow[t]{2}{*}{4.} & 50 -60years & 10 & 6 & 10 & 8 & 20 & 14 \\
\hline & Total & $\begin{array}{c}35 \\
(28 \%)\end{array}$ & $\begin{array}{c}21 \\
(16,8 \%)\end{array}$ & $\begin{array}{c}43 \\
(34,4 \%)\end{array}$ & $\begin{array}{c}24 \\
(19,2 \%)\end{array}$ & $\begin{array}{c}80 \\
(65,4 \%)\end{array}$ & $\begin{array}{c}45 \\
(34,6 \%)\end{array}$ \\
\hline
\end{tabular}

of rehabilitation, but also to evaluate the effectiveness of the applied schemes and technologies of orthopedic treatment, which determined the purpose of our investigation.

\section{THE AIM}

Study of the evaluation the patient's quality of life with muscular and joint dysfunction of TMJ with using a modified profile questionnaire at various stages of orthopedic treatment.

\section{MATERIALS AND METHODS}

The study was conducted at the Department of Orthopedic Dentistry on the base of University Dental Center in Kharkiv National Medical University.

Deontological aspects are resolved taking into account the legislation in Ukraine, the Law of Ukraine "About Medicines», 1996, Art. 7, 8, 12, principles of ICH GCP (2008), order of the Ministry of Health of Ukraine No. 690 of 23.09.2009 «On Approval of the Rules for Clinical Trials and Expertise of Materials of Clinical Trials and Model Regulations on the Ethics Commission», as amended; World Health Association Declaration of Helsinki. The study was performed with minimal psychological loss for patients. Patients were fully informed about the purpose and methods of the study, the potential benefits and risks, and the possible discomfort with the diagnosis and treatment. All ethical requirements for maintaining the confidentiality of the information received during the study are fulfilled. The work was reviewed and approved by the Bioethics Commission of the KNMU of the Ministry of Health of Ukraine.

We conducted a clinical examination and subjective analysis of 125 patients aged 20 to 60 years (mean age $38.5 \pm$ 3 ), and 80 of them with a reliable diagnosis of dysfunction of TMJ and a control group of 45 patients of the same age without pathology of TMJ.

The main criteria for the selection of orthopedic patients in the study of quality of life were: gender-based distribution: men / women; age of patients - from 20 to 60 years; distribution into 4 groups according to the level of the disease and the etiological causes of its occurrence $[11,12]$.
To determine the social characteristics of patients and the level of their quality of life and creation of profile questionnaire, we used specific research methods, namely: asking information, formation and scaling of the results of the questionnaires; statistical methods of data processing (use of informative indexes); analysis and interpretation of the results.

Clinical infomation were obtained by conducting an extensive dental examination using the «Dental Status Assessment Card» according to WHO, $1995[11,13]$. The result of the clinical examination was important for further diagnosis and choice of orthopedic treatment.

Assessed the presence of pain in the face, head and neck, in case of detection - took into account their localization, the timing and causes of occurrence, duration. Identified complaints of joint noise, its nature and causes. Psycho-emotional and general condition were evaluated.

In a state of physiological rest there was an examination of the patient in the central, anterior and lateral occlusions, as well as at the maximum opening of the mouth. The height of the lower third of the face, the severity of nasolabial and chin folds were evaluated. The position of the mandible was determined relative to the frontal, horizontal and sagittal planes. At the same time recorded the degree of mouth opening, winding movements, amplitude of the front and side movements of the jaw. [7, 14, 15].

Palpation of the TMJ was performed in a state of physiological rest, with the closure of the jaws in central occlusion, and during the movement of the mandible. The studies were performed externally in front of the goat ear, as well as through the external auditory canal. The presence of tenderness, the degree of excursion of the heads of TMJ, the synchrony of their movement, the presence of joint noise, the time of its manifestations and the nature of obstacles of sliding movement were evaluated.

The standardization of the data collection procedure was ensured by the unified nature of the survey and registration of epidemiological material using questionnaires: a general WHOQoL-100 quality of life questionnaire (WHOQoL Group, 1993) and a specialized dental quality questionnaire OHIP-14 (G. Slade, 1993) and our profile questionnaire $[4,12]$. 
Table 2. Profile quality of life questionnaire for patient with muscular and joint dysfunction of TMJ

\begin{tabular}{|c|c|c|c|c|c|c|}
\hline \multirow[b]{2}{*}{1} & \multicolumn{2}{|l|}{ Questions } & \multicolumn{3}{|c|}{ Criteria of answers } & \multirow[b]{2}{*}{7} \\
\hline & 2 & 3 & 4 & 5 & 6 & \\
\hline \multirow{5}{*}{ 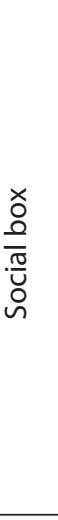 } & $\begin{array}{l}\text { Point criteria } \\
\text { (5- point scale) }\end{array}$ & 1 point & 2 points & 3 points & 4 points & 5 points \\
\hline & $\begin{array}{c}\text { How do you evaluate the } \\
\text { quality of your life? }\end{array}$ & bad & unsatisfactorily & satisfactorily & good & perfectly \\
\hline & $\begin{array}{c}\text { How satisfied are you with } \\
\text { your health? }\end{array}$ & bad & unsatisfactorily & satisfactorily & good & perfectly \\
\hline & $\begin{array}{l}\text { How healthy is the } \\
\text { environment around you? }\end{array}$ & bad & unsatisfactorily & satisfactorily & good & perfectly \\
\hline & $\begin{array}{l}\text { How often have you had } \\
\text { negative condition, such } \\
\text { as bad mood, despair, } \\
\text { depression? }\end{array}$ & always & often & sometimes & seldom & never \\
\hline \multirow{7}{*}{ 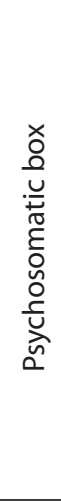 } & $\begin{array}{l}\text { Point criteria } \\
\text { (5- point scale) }\end{array}$ & 1 point & 2 points & 3 points & 4 points & 5 points \\
\hline & $\begin{array}{l}\text { Restrictions on chewing } \\
\text { function }\end{array}$ & full & almost full & partial & temporary & not exist \\
\hline & Physycal pain & always & often & sometimes & seldom & never \\
\hline & Psychological discomfort & always & often & sometimes & seldom & never \\
\hline & Physical disability & full & almost full & partial & temporary & not exist \\
\hline & Psychological disability & full & almost full & partial & temporary & not exist \\
\hline & $\begin{array}{c}\text { Social } \\
\text { disability }\end{array}$ & full & almost full & partial & temporary & not exist \\
\hline \multirow{13}{*}{$\frac{\stackrel{x}{0}}{\frac{\AA}{\pi}}$} & $\begin{array}{l}\text { Point criteria } \\
\text { (5- point scale) }\end{array}$ & 1 point & 2 points & 3 points & 4 points & 5 points \\
\hline & Feeling weak, tired & always & often & sometimes & seldom & never \\
\hline & Head pain & always & often & sometimes & seldom & never \\
\hline & Pain in the parotid area & always & often & sometimes & seldom & never \\
\hline & $\begin{array}{c}\text { Swelling of the soft tissues } \\
\text { of the parotid region }\end{array}$ & always & often & sometimes & seldom & never \\
\hline & Tinnitus & always & often & sometimes & seldom & never \\
\hline & Clicking in the joint & always & often & sometimes & seldom & never \\
\hline & $\begin{array}{l}\text { Difficulty opening the } \\
\text { mouth }\end{array}$ & always & often & sometimes & seldom & never \\
\hline & Oral hygiene & bad & unsatisfactorily & satisfactorily & good & perfectly \\
\hline & Pain feelings during eating & always & often & sometimes & seldom & never \\
\hline & Abrasion of teeth & always & often & sometimes & seldom & never \\
\hline & $\begin{array}{l}\text { Breaking of occlusion } \\
\text { relationships }\end{array}$ & always & often & sometimes & seldom & never \\
\hline & $\begin{array}{c}\text { Breakage / correction of } \\
\text { denrures }\end{array}$ & always & often & sometimes & seldom & never \\
\hline
\end{tabular}

\section{RESULTS AND DISCUSSION}

The distribution of examined patients was due to specific differences in the clinical features of the TMJ depending on the sex and different age periods, the data of which are presented in Table 1.
The quantitative indicators are shown as follows: men with TMJ dysfunction - 35 patients (28\% of the total number of examined), women with dysfunction of the TMJ -43 patients (34.4\% of the total number of surveyed), men without pathology of the TMJ - 43 patients (34.4\% 
Table 3. Conversion Scale: Quality of Life Assessment of Patients with TMJ muscular and joint dysfunction

\begin{tabular}{|c|c|c|c|c|c|c|c|c|c|}
\hline \multirow{3}{*}{ № } & \multicolumn{6}{|c|}{$\begin{array}{c}\text { Result } \\
\text { (total point for one examination) }\end{array}$} & \multirow{2}{*}{\multicolumn{2}{|c|}{ Total }} & \multirow{3}{*}{ Result } \\
\hline & \multicolumn{2}{|c|}{ Before treatment } & \multicolumn{2}{|c|}{$\begin{array}{l}\text { After } 1,5 \text { months of } \\
\text { starting treatment }\end{array}$} & \multicolumn{2}{|c|}{$\begin{array}{l}\text { After } 3 \text { months of } \\
\text { starting treatment }\end{array}$} & & & \\
\hline & Point & $\%$ & Point & $\%$ & Point & $\%$ & Point & $\%$ & \\
\hline 1 & $100-110$ & $30 \%$ & $100-110$ & $30-35 \%$ & $100-110$ & $40 \%$ & & & A \\
\hline 2 & $88-99$ & $20-25 \%$ & 88-99 & $20-25 \%$ & $88-99$ & $30-35 \%$ & & & $\mathrm{~B}$ \\
\hline 3 & $66-87$ & $20-12 \%$ & $66-87$ & $35 \%$ & $66-87$ & $20-30 \%$ & & & C \\
\hline 4 & $44-65$ & $15 \%$ & $44-65$ & $15-20 \%$ & $44-65$ & $25 \%$ & & & $\mathrm{D}$ \\
\hline 5 & $22-43$ & $5-10 \%$ & $22-43$ & $5-10 \%$ & $22-43$ & $10 \%$ & & & $\mathrm{~F}$ \\
\hline
\end{tabular}

of the total number of examined), women without the pathology of the TMJ -19 patients $(21.2 \%$ of the total number of patients).

It is important to note that patients of group 1 were selected with dysfunctions, which were caused in most cases by psycho-emotional disorders, spine diseases, patients of group 2 - diseases of spine, arthritis, arthrosis. Group 3 had a history of occlusion disorders and arthritis.

Examining these complaints and conducting the questioning of the investigated patients, we created a sample of questions that reflected the actual quality of life problems of orthopedic treatment of dysfunction of the TMJ, the contents of which are presented in our modified profile questionnaire in Table 2.

Our profile questionnaire is intended for filling by the respondent (patient) at the three control stages of orthopedic treatment under the supervision of an orthopedic dentist (before the start of treatment, 1.5 months after the beginning of treatment and 3 months after the beginning of treatment). The data obtained were subjected to a scaling process, converted into percentages to facilitate statistical analysis. The answers to the questions were evaluated as a percentage, according to the result conversion scale shown in Table 3.

The testing phase was accompanied by a preliminary psychometric evaluation of the questionnaire: assessment of the frequency distribution of answers to the questions; reliability assessment (Cronbach's coefficient on questionnaire scales); assessment of construct validity (analysis of questionnaire factor structure and correlation relationships within its structure). In compliance with all the above requirements, the final version of the questionnaire was formed, taking into account the results of the pilot testing.

The answer to each question, depending on the severity of the situation was evaluated in the number of points from 1 to 5 (from the lowest degree to the highest).

The results of the first test showed that, in general, all the questions and answer options were clear to the patients and did not cause much difficulty in the examination. The average length of time a respondent completed the profile questionnaire was up to 15 minutes.

The worst values before and after treatment were found in the $3 \mathrm{rd}$ and 4 th age subgroups ( $30.5 \pm 0.60$ and $42.0 \pm 0.7$ points, respectively), with a mean of 10 and $13 \%$, respec- tively, according to the proposed rating scale. In this case, the indicators have changed 1.3 times in the direction of increase. The highest level of QL was observed in patients of the $2 \mathrm{nd}$ ( $98.7 \pm 0.8$ points) and the 1st subgroups (102.3 \pm 0.4 points), the average value for the three stages of treatment was $78 \%$ and $92 \%$ rating scales. Before of orthopedic treatment, the values were approximately the same.

\section{CONCLUSIONS}

The analysis of our sinvestigations shows that the use of a profile questionnaire of quality of life in patients with muscular and joint dysfunction of the TMJ is appropriate. The questionnaire can be used to evaluate the dynamics of orthopedic treatment of this complex pathology, and it can also be used as a prognostic criterion for the end of the disease.

In our patients of the general sample, the average score increased in the short term (1.5 months) after the start of orthopedic treatment and the values significantly changed towards improvement after 3 months, indicating a positive dynamics and correctness in the choice of orthopedic treatment for patients with muscular and joint dysfunction of the TMJ at the clinic of orthopedic dentistry.

In the treatment of patients of 1 age subgroup, the result of which was $(93,38 \pm 1,19$ and $89,3 \pm 2,6$ points); also patients of the 4 th subgroup (102,3 $\pm 0,4$ points). Longterm outcome of prosthetics, namely after 3 months of orthopedic treatment $(102.4 \pm 0.5$ and $106.8 \pm 1.9$ points) and (108.86 \pm 0.9 points), which indicates a significant improvement in quality of life patients.

The dependence of quality of life on orthopedic treatment for with muscular and joint dysfunction of the TMJ is significant, and treatment, in turn, leads to an improvement in the quality of life of the patients. That is why the results of investigations presented in this article make it possible to practically use the questionnaire in assessing the quality of treatment in the practice of orthopedic dentists.

\section{REFERENCES}

1. Yakobchuk A.V., Dementieva 0.V., Tsanko I.I., et al. Theoretical and methodological aspects of improving the quality of dental care in Ukraine. The Taurian Medico-Biological Bulletin. 2012;15(2):279-281. (In Ukranian). 
2. Lunkova Y.S., Novikov V.M. Analysis of changes in quality of life in patients with unilateral subluxations of the TMJ during treatment. Ukrainian Dental Almanac. 2012;3:39-42. (In Ukranian).

3. MakeevV.F., KucherA.R., RibertY.A.,Zhiznomirskaya 0.0.Ultrasonography in the diagnosis of degenerative changes of the temporomandibular joint. Bulletin of problems of biology and medicine. 2016;1(2):78-95.

4. Yanishen I.V., Pogorila A.V., Sidorova 0.V., et al. Comparative evaluation of the effectiveness of orthopedic treatment of patients with partial and new missing teeth based on quality of life. KNMU. 2019;164-170. (In Ukranian).

5. Petrikas I.V., Zhirkov A.M., Krasnov A.A. Comprehensive interdisciplinary approach to the prevention and treatment of TMJ dysfunction. Problems of dentistry.2016;1:79-84. (In Ukranian).

6. Sischo L., Broder H.L. Oral health-related quality of life: what, why, how, and future implications. Journal of dental research. 2011;1:1264-1270.

7. Lunkova Y.S., Bereziy M.V., Novikov V.M. The results of the evaluation of patients' quality of life in the dynamics of orthopedic treatment in dislocations of the meniscus of the temporomandibular joint. Actual problems of modern medicine: Bulletin of the Ukrainian Medical Dental Academy. 2017;17(2): 58. (In Ukranian).

8. Wen J., Yk S., Yp L., et al. Quality of life. Physical Diseases, and Psychological Impairment among Survivors. 2012;3:435-443.

9. Wolford L.M. Autologous fat grafts placed around temporomandibular joint (TMJ) total joint prostheses to prevent heterotopic bone. Springer, Berlin, Heidelberg. In Autologous fat transfer, 2012;2:361-382.

10. Novikov V.M. Quality of life and its evaluation in the course of treatment of patients with musculoskeletal dysfunction of the temporomandibular joints. Current issues and problems of the development of dentistry at the present stage: a collection of scientific papers. 2011: 59-62. (In Ukranian).

11. Yanishen I..V, Berezhna 0.0., Kuznetsov R.V. Factors that determine the quality of orthopedic structures: Relationship analysis. Bulletin of problems of biology and medicine. 2016;1(2): 45-49. (In Ukranian).

12. Bida V.I., Klochan S.M. Orthopedic treatment of patients with occlusal articulation syndrome of the temporomandibular joint. Ukrainian Dental Almanac. 2012. 3; 45-52. (In Ukranian).

13. Novik A.A., Ionova T.I., Shevchenko Y.L. A guide to the study of quality of life in medicine. 2007:320. (In Ukranian).
14. Eliashova A. Initial conditions for the application of a rational model of prevention of dental diseases in Ukraine. 2015. (In Ukranian).

15. Staquet M.J. Quality of life assessment in clinical trials [0xford University Press: Oxford, New York, Tokyo].1998;360.

The research is a part of the comprehensive research program of Kharkiv National Medical University, The Ministry of Healthcare of Ukraine, Department of Orthopedic Dentistry "Optimization of methods of diagnosis and treatment of major dental diseases» (State registration number 0116U002899; 2019-2021).

\section{ORCID and contributionship:}

Igor V. Yaishen: 0000-0003-4278-5355 ${ }^{A, B}$

Karina Y. Andrienko: 0000-0002-5453-6834 ${ }^{\mathrm{C}}$

Irina O. Pereshivaylova: 0000-0002-9360-1600 ${ }^{D}$

Leah G. Salia: 0000-0002-3807-5468 ${ }^{\mathrm{E}}$

Elena O. Berezhna: 0000-0003-4221-4608 ${ }^{F}$

\section{Conflict of interest:}

The Authors declare no conflict of interest

\section{CORRESPONDING AUTHOR}

\section{Karina Y. Andrienko}

Kharkiv National Medical University

4 Textile st., 61000 Kharkiv, Ukraine

tel. +380636903378

e-mail:Andrienko_Karina@ukr.net

Received: 12.03 .2020

Accepted: 19.06 .2020

A - Work concept and design, B - Data collection and analysis, C - Responsibility for statistical analysis, $\mathbf{D}$-Writing the article, $\mathbf{E}$-Critical review, $\mathbf{F}$ - Final approval of the article 